Article

\title{
Legitimate Exclusion of Would-Be Immigrants: A View from Global Ethics and the Ethics of International Relations
}

\author{
Enrique Camacho-Beltrán ${ }^{1,2}$ \\ 1 Faculty of Philosophy, Panamericana University, Mexico City 03920, Mexico; \\ enrique.camacho@comunidad.unam.mx \\ 2 Faculty of Philosophy, National University of Mexico, Mexico City 04510, Mexico
}

Received: 30 March 2019; Accepted: 4 August 2019; Published: 9 August 2019

check for updates

\begin{abstract}
The debate about justice in immigration seems somehow stagnated given that it seems justice requires both further exclusion and more porous borders. In the face of this, I propose to take a step back and to realize that the general problem of borders-to determine what kind of borders liberal democracies ought to have-gives rise to two particular problems: first, to justify exclusive control over the administration of borders (the problem of legitimacy of borders) and, second, to specify how this control ought to be exercised (the problem of justice of borders). The literature has explored the second but ignored the first. Therefore, I propose a different approach to the ethics of immigration by focusing on concerns of legitimacy in a three-step framework: first, identifying the kind of authority or power that immigration controls exercise; second, redefining borders as international and domestic institutions that issue that kind of power; and finally, considering supranational institutions that redistribute the right to exclude among legitimate borders.
\end{abstract}

Keywords: distributive justice; political legitimacy; international legitimacy; liberal theory of international relations; immigration; political self-determination; territorial rights; nationalism; statism

\section{Introduction}

For some exclusionist liberal political theorists, the conception of social justice among residents and citizens provides reasons for excluding would-be immigrants, so borders should remain closed until we have enough reason to admit someone (Miller 2016; Wellman and Cole 2011). However, some other inclusionist theorists believe that justice requires just the opposite: porous borders that remain open until we have sufficiently strong reason to exclude someone (Carens 2013; Kukathas 2005; Wellman and Cole 2011). This seems insufficient if we have to believe that social justice may require both inclusion and exclusion at the same time.

In spite of this, I propose to take a step back to the domain of global ethics and the ethics of international relations. From there, if distributive justice matters, then maybe the permission to exclude would-be immigrants should be distributed, not from the point of social justice alone but from the holistic view of global ethics. However, I arrive there following three steps of analysis. In the first stage, instead of asking what justice requires from our border institutions, I suggest asking first a logically prior question: At the level of our most basic moral principles, what kind of authority is it permissible that borders exercise? This, I believe, is the question of legitimacy. Secondly, we realize that borders are not only lines in the ground or the limits of our institutions but also institutions themselves. Borders are the institutions which carry out the authority of border controls over would-be immigrants. These sui generis institutions are not only domestic and, therefore, subject to standards of distributive justice for residents and citizens but also international and subject to standards of international legitimacy that 
should take the interest of outsiders into account. This account of borders allows to weigh together social justice and global ethics, so it may show us under what conditions it will be morally permissible for borders to prioritize the interest of residents and citizens over the interest of would-be immigrants. Thirdly, once we draw the contours of the legitimate use of border authority, we can again ask whether it is appropriate to distribute the right to exclude immigrants according to standards of distributive international justice by means of an international border institution.

This approach has the potential to deflate the tension between inclusionists and exclusionists because the three stages may identify the kind of stances of border authority we typically use to protect relationships of justice between citizens and residents that are nonetheless morally impermissible from the point of view of international legitimacy and that, therefore, should be avoided. Here, I do not provide a substantive answer to the problem of what morality, all-things-considered, requires from immigration controls. Neither will I make a substantive case for exclusion or inclusion. Instead, I merely outline the contours of an alternative way to frame the problem by assembling three somewhat different approaches. I identify the problem by means of a critical interpretation: the conflation of concerns of justice and concerns of legitimacy may hinder the incorporation of the interest and rights of potential immigrants in the justification of immigration controls. This interpretative thesis is supported by evidence gathered by a conceptual analysis of the conceptions of legitimacy and justice. Finally, my three-step approach employs the deontological approach of applied ethics, global ethics, or the ethics of international relations.

The paper is structured as follows. In Section 2, I will explain how the literature about justice in immigration has reached an impasse by distinguishing between exclusionist and inclusionist accounts of immigration policy and the conflictive requirements of justice in each case. In Section 3, I will distinguish legitimacy and justice as two different virtues or evaluations of political institutions and how they are intermingled in what we call political justice in the postrawlsean literature. Section 3, in turn, shows how political justice is embedded in the conventional view of the ethics of immigration. This is important because, while contemporary political theory often takes them as the same evaluation, there is a marked tendency in the exclusionist literature of justice in immigration to insist that what justice for citizens and residents requires from our border controls is also a legitimate use of power over outsiders. I also try to explain how this is wrong in the sense that exclusionist justifications of immigration controls normally beg the question by assuming that borders are legitimate and that states have a legitimate claim over their territories. In Section 4, I lay down my three-step approach to problems of the ethics of immigration. I explain how a political conception of legitimacy may be applied to the authority that borders typically exercise. I also scratch my conception of borders and the different sources from where border institutions may draw legitimacy from. Hopefully, my "alternative new normative start" provides a more coherent view of what morality requires from our border institutions. Finally, in Section 5, I deal with two possible objections to my three-step approach.

From the outset, some clarifications are needed. Firstly, I am only concerned with borders of liberal democracies. This is because the institutions of these kind of states are permeable to moral principles such as human rights, equal citizenship, and some form of equality of opportunity. Elsewhere, I have argued how the moral character of liberal democracies implies that borders, too. should be understood as institutions permeable to these kind of principles (Camacho 2016). There is, of course, a more general narrative that tells us about how states and borders came about (Castañeda and Schneider 2017), but there is also a narrative that tells us how states and borders may change. This paper is about the second kind of narratives and issues as we may find them in the liberal ethics of international relations.

Secondly, among would-be immigrants, there are several categories with different needs and dissimilarities (Miller 2016). For example, most exclusionist writers believe that refugees have a very strong moral claim to be admitted, grounded in their most basic needs (Miller 2016; Carens 2013; Wellman and Cole 2011). Presumably, each case may offer its own reasons to limit or expand the right to exclude. However, I worry that, in difficult cases, most of the normative work is performed by the vulnerability and urgency of the case and not by the relationship between citizens, residents, land, 
institutions, and potential immigrants. It seems to me that a good approach to the ethics of immigration needs to first make an account of that complex relationship between those elements above and, after that, to work out the difficult cases. Therefore, by holding constant further complicating factors, I wish to isolate the normative core of claims to exclude (Fine and Sangiovanni 2015). In order to do that, I will focus only on the claim to admission and the interest of exclusion that is typically recognized as the weakest: would-be immigrants who wish to be admitted because they want different opportunities to work, to acquire skills, or to engage in forms of culture or religion or ways of caring about others that are not available in their countries of origin, etc. They are not refugees, they are not seeking to reunite with family members, and they are not suffering severe economic or other deprivation or, indeed, suffering any substantive and systematic violation of rights where they live. They could very well remain home, but they simply wish to improve their expectations, experiences, and options. Similarly, I assume that the right of exclusion is not the result of a state of crisis from the part of receiving states (Camacho 2017). They are not suffering from a financial crash or debt burdens, their labour markets are not overflowing, they are not flawed states without political order and just institutions, they are not facing terrorist threats or another sort of security crisis, and so on. They simply wish to secure the protection of their citizens' wellbeing, particularly of the worst-off or the more vulnerable (Macedo 2018). I will call this "the core case". Proceeding in this way may be problematic, but I focus on this group mainly because the aim of the paper is to establish some guidelines to frame questions of immigration; therefore, taking up the weakest case for inclusion/exclusion and to determine under what conditions, if any, states/would-be immigrants even have a pro tanto right to exclude/being included should be helpful for drawing an approach that could later consider the possibility of whether states or would-be immigrants may have an all-things-considered case (Fine and Sangiovanni 2015, p. 194). If my three-step approach here is sound, then later, each step needs to be developed further. Most obviously, my account of borders and the legitimate claims over the land need to be given substantive content. However, future work will develop this.

\section{The Conventional View about Immigration: A Critical View}

Consider first the pro tanto case for exclusion as a requirement of justice. Roughly, many liberals endorse the version that follows:

Exclusionism: Justice not only permits but even requires exclusionary borders with the pro tanto right to exclude would-be immigrants because citizens have a legitimate claim over the almost exclusive enjoyment of their opportunities and advantages grounded in a strong case of political self-determination.

A people or a group of citizens gain or lose rights of political self-determination in virtue of how they stand together in a special, intrinsically valuable relationship to one another provided that, together, they have developed institutional devices for protecting their own rights and freedoms and effective forms of mutual care. According to exclusionists, these relationships of justice among members may be jeopardized if outsiders are let in because outsiders are not entitled to the benefits and opportunities created by these relationships of justice across generations. ${ }^{1}$ This provides states

1 For instance, in the Law of Peoples, Rawls stated that it is not permitted to migrate into other people's territory without consent and that the state is the agent qualified to enforce this: "an important role of government, however arbitrary a society's boundaries may appear from a historical point of view, is to be the representative and effective agent of a people as they take responsibility for their territory and its environmental integrity, as well as for the size of their population." (Rawls 2001a, p. 38). This intuition is supported by the justness of private property: "Unless a definite agent is given responsibility for maintaining an asset and bears the responsibility and loss for not doing so, that asset tends to deteriorate. On my account the role of the institution of property is to prevent this deterioration from occurring. In the present case, the asset is the people's territory and its potential capacity to support them in perpetuity and the agent is the people itself as politically organized. The perpetuity condition is crucial. People must recognize that they cannot make up for failing to regulate their numbers or to care for their land by conquest in war, or by migrating into another people's territory without their consent." (Rawls 2001a, p. 8). 
with a good case for restricting immigration. ${ }^{2}$ Roughly, David Miller and Christopher Heath Wellman, among others, endorse this view. ${ }^{3}$ The problem with exclusionism is that some other liberals extract different conclusions from standards of political justice. Consider the following position:

Inclusionists: Justice requires vastly porous borders because all humanity has a legitimate claim over certain forms of international freedom of movement and association or certain forms of global equality of opportunities. As a result, the relevant set of individuals where relationships of justice must be established is in principle unbounded or is global in scope.

Under inclusionism, duties between citizens and their case of self-determination do not have to necessarily outweigh their general duties to would-be immigrants provided that they also stand in a special relationship with all other human beings. Joseph Carens, Chandra Kukathas, Philip Cole, and Matthias Risse are the central proponents of this view. Both sides are vulnerable to many objections, which will be discussed later in Section 4. For now, notice that, from these positions, immigration poses the following contradiction: there are, on both sides of the border, individuals with basic interests and powerful reasons for exclusion or inclusion, so it is not clear what justice requires from immigration restrictions. ${ }^{4}$ Do citizens of affluent states have the right to benefit from the status quo at the cost of immigrants? Do immigrants have the right to participate in the institutions and benefits that distant others have created over generations? What can we make of this contradiction? One possible critical interpretation is that considerations of justice are not very good by themselves in adjudicating controversies about immigration policies. By means of conceptual analysis, I will try to support this interpretation and argue that the contradiction above is in part the result of the conflation between evaluations of justice and evaluations of legitimacy even though this conflation is pervasive on contemporary political theory.

Even though philosophers still disagree greatly about the conceptual distinction, they agree that, as a concept, justice is concerned with what we owe to whom. They also agree that the other central question of politics often identified with legitimacy is to discern when political power is justified in order to be seen as authoritative and bonding in a way compatible with basic freedoms. ${ }^{5}$ To sum up, we can make the following distinction: an institution has the following political virtues:

legitimacy when it takes decisions in the name of others and uses coercive power to enforce those decisions, providing reasons that bind those subjected to those decisions. This entails that those subjected to the institutional decisions would be wrong to resist those decisions. (Williams 2005)

justice when it gives to everyone involved in the institutional framework and scope of action what they are entitled to. Typically, this means that it distributes the burdens and advantages of cooperation within the institutional scope. (Barry 1991)

2 Exclusion of outsiders is conditional to considerations of human rights. This means that exclusion needs to give equal concern to the demands and needs of outsiders, so the putative right to exclude has many qualifications, that is why it is a pro tanto right. Justice has many currencies. From the point of view of exclusionists, distributive justice is the standard appropriate for treating citizens, but equal concern only demands the respect for human rights regarding international relations. See (Cohen 2004; Beitz 2011) for discussion.

3 They, of course, have different and opposing views about what considerations of justice count. Miller is largely concerned with cultural justice or associative obligations between members of the same cultural nation, while Wellman is concerned with rights of association. However, despite their different starting points, both share the view that the value of political self-determination and the interest that members have with it is such that it trumps the interest of outsiders to a certain extent.

4 This way of distinguishing theories of immigration may be controversial. One reason is that a given account may not fit perfectly into my two simplifications. However, for the purpose of this paper, these simplifications help us to focus in the standards we use to assess immigration restrictions. Later, I will come back to my simplifications and explain how they are related to the debate of immigration in the broader field of global ethics.

5 For instance, Hobbes and Locke were more interested in reconciliating authority with human liberty by means of justification than in the secondary (for them) problem of the moral quality of coercive power (Hobbes 1968, pp. 161, 183, 126, 190; Locke [1689] 1988, pp. 210, 280, 293). Kant, on the other hand, believed that the problem of justifying political authority was not different from the problem of its quality because the function of the state was, in the end, to protect our rights in the sense of creating and sustaining just institutions (Kant [1781] 1991). Therefore, in a sense for Kant, the state's legitimacy was grounded in its ability to bring about justice (Kant [1781] 1991, pp. 408-10; MM Ak 6, pp. 255-56). 
These very general concepts of justice and legitimacy may be narrowed down for the specific moral character of liberal democracies (Scanlon 1998; Barry 1991; Rawls 2001b). Legitimacy concerns who is entitled (and to what extent) to take decisions in the name and interest of others, and justice concerns the distribution of burdens and benefits from social cooperation (Valentini 2012; Quong 2011; Rawls 2001b). Now, notice that, under this distinction, the basic structure of liberal societies is one familiar case where both standards may be conceptually co-extensional in the sense of applying greatly to the same object (Sleat 2015; Rossi 2014; Song 2012; Peter 2009; Simmons 2001). ${ }^{6}$ As a result, it is not at all surprising that most philosophers have regarded standards of legitimacy and justice as the same evaluation (Valentini 2012; Simmons 1999). For instance, according to Valentini, political justice collapses the underlining concerns of legitimacy and justice by indicating the different requirements of equal concern under different circumstances: Legitimacy tells us when institutions may permissibly coerce us, while justice determines what institutions owe to those coerced (Valentini 2012, pp. 97, 594). For simplicity, I will call political justice the view that collapses justice and legitimacy as the same evaluation.

Now after this conceptual refinement, we can restate the question of the last section: What does political justice—-legitimacy and justice together—demand from our border institutions? Does political justice require harder borders or rather more porous ones? I will argue that this tension between conflicting claims of justice coming from exclusionism and inclusionism are in part the result of the overlapping of concerns of justice and concerns of legitimacy. I will argue as well that this flaw in the approach may be overcome by my three-step approach.

\section{Residents, Citizens, and Land}

We often believe unreflectively that the interest and rights of valuable political communities involve analytically controlling the land. In order words, we believe that what justifies the state justifies its authority over its borders and the territory within. In this section, I will show that the conventional account of justice in immigration - exclusionists and inclusionists—-fail to offer a principled connection between political communities and land. On one hand, exclusionism takes into account the interest of residents and citizens but begs the question of the grounds of an immigration policy. Inclusionism, on the other hand, takes into account the relationship between borders and land but fails to give right weight to the claims and concerns of would-be immigrants and political communities here and now. From this, I hope I can show what I suggested in Section 2: that the requirements of political justice are ill-conceived to deal only by themselves with problems of the morality of immigration because they tend to beg the question of legitimacy. I will not attempt, however, to provide a full account for the ethics of exclusion. To be excluded from the land and to be excluded from the group have very different meanings and normative consequences. It is worth noting that exclusion is not one thing but many. For instance, it may not be equally harmful to exclude low-skilled would-be immigrants from the land and to exclude highly qualified immigrants from well-paid jobs. These cases and many others need to be carefully surveyed and catalogued. Many of them will fit into the core case, but I will not engage in that discussion here. For my purposes here, it is enough to show that the conventional view neglects to take into account the exclusion from the land as a resource needed for participating in valuable legitimate institutional relations. ${ }^{7}$

Consider first one central example of exclusionism that I will call rights-statism. According to the view defended by Christopher $\mathrm{H}$. Wellman, citizens and residents have a pro tanto right for

6 Famously, Rawls, after A Theory of Justice, eventually came to believe that it is not possible to argue for justice as fairness in terms of the goodness of justice without making it unacceptable for the citizens of a pluralistic society since citizens have different and irreconcilable ideas about what is good and just (Song 2012, pp. 153-61). The Rawlsean problem of justification of a theory of justice shifts then from an argument of the justness undertaken by a comprehensive theory of morality (Rawls 1971, p. 4) to an argument of the legitimacy of justice as fairness capable to elucidate: "in the light of what reasons and values-of what kind of a conception of justice-can citizens legitimately exercise that coercive power over one another?" (Rawls 2001b, p. 41). That is why, for that specific problem as framed by Rawls, justice and legitimacy overlap.

7 Many thanks to an anonymous reader for raising this problem to me. 
political self-determination (Wellman 2008). This kind of control that communities of residents and citizens exercise in their self-regarding affairs must entail political rights of association, which in turn also entail analytically a legitimate right to be free from unwanted associations, such as those with unwanted would-be migrants. As an exclusionist view, rights-statism does not deny stringent duties of global justice.

There are many reasons to resist Wellman's argument (Van der Vossen 2015; Hidalgo 2012; Fine 2010). For one, political self-determination does not necessarily entail permissibility of any particular policy, including policy about immigration controls (Hidalgo 2012, p. 16). Therefore, the putative analytical connection between rights of political self-determination and rights of exclusion is not obtained. Furthermore, rights-statism does not establish any kind of position of dominion over the land from which defenders of exclusionism wish to exclude nonmembers. Here is the flaw: we can accept that there is a pro tanto case for exclusion from the group without accepting the further claim that there is a pro tanto case for exclusion from the land or the territory (Carens 1987; Simmons 2001; Fine 2010). This means that the proper ground to assess immigration policy should begin with a resource-based justification of their claims for exclusion from the homeland. Without it, the option to dismiss the basic interest in immigrating would-be migrants may be at least questionable because those enforcing exclusion will not have a privileged position of dominion over the homeland.

However, this is too quick because these objections only show that rights-statism is inconclusive. The possibility to supplement forms of exclusionism may come from associative obligations. Some of the relationships we establish with each other are special in the sense that, without actually providing our consent, we engage in reiterative valuable interactions that are instrumentally valuable. If the history of these interactions becomes more intimate and creates trust, cooperation, and interdependence, then these relationships may become intrinsically valuable as well, so typically, we find we have reasons to feel obligated when we play certain roles such as that of a friend or a citizen even if we have never provided our consent (Scheffler 2002). Accordingly, a state is legitimate when it protects the nation and the special bond members share associative obligations. To threaten the production of these goods seems also deeply unjust. Therefore, from the view of associative obligations, exclusionist immigration policy is legitimate, grounded in reasons of justice. (Miller 2016, p. 27). This view that I call obligations-statism, has been pursued mostly by liberal nationalists (Tamir 1993; Miller 1995; Gans 1998).

Miller's interpretation of obligations-statism is attractive because it supplements the case for rights of associative obligations with a resource-based account of border control of land. According to Miller, the unique way that a nation develops politically, economically, and socially has a territorial dimension because culture amalgamates with the land in a way that will be extremely harmful to members of the nation to be deprived from the space where their own culture is territorially incarnated. Therefore, it is not the fact of individual ownership that grounds territorial rights; rather, it is the fact that a community mixes its own culture with the soil in a way that it is not detachable without causing an enormous collective harm (Miller 2007, p. 218). ${ }^{8}$

There are many challenges raised against obligation-statist arguments for immigration control. For instance, it seems that nationalist protection of culture by means of state institutions seems to accomplish just the opposite: the coercive imposition of a form of unauthentic official culture devised by state officials instead of organically conducted by members of the cultural group (Camacho 2017). However, the main problem with the nationalist account of territorial control is that the deontic force of a state's claims is grounded on the idea that cultural self-determination may be necessarily

8 According to Locke, a state's dominion over territory is a consequence or derives from member's prior ownership rights. Members with private property transfer certain property-powers to the state in exchange, at least, for the protection of their property by the state. In this way, owners cease to have absolute dominion over their property and states end up with certain dominion over a territory, establishing a group or an association of co-owners (Locke [1689] 1988, pp. 288-348; Simmons 2001). The main problem with this account is its historic implausibility. It seems descriptively false that acquisition, property, and transaction could fulfil appropriate criteria of justice that could preserve, in turn, a deontic ground for a state's dominion (Blake and Mathias 2008, p. 8). 
connected with land but it is not obvious that the connection between labour-culture mix with collective jurisdictional rights is necessary or sufficient to ground authority over the land, at least not the kind of authority that allows immigration exclusion (Stilz 2011, p. 577). A nation may have rights over their social construction of territory, but they attempt to exclude would-be immigrants from the land and not from their imagined or socially constructed heartland. This means we can find the same flaw again. An account of associative obligations that explains how inclusion may be unjust for residents and citizens simply assumes that immigration controls are legitimately imposed over potential immigrants. However, even if we grant that the interest of citizens and residents in their territorially located culture could provide reasons to take control over the process of change of their culture, this hardly will provide reasons to justify the administration of immigration. Certainly, it does not necessarily provide reasons for an exclusionist immigration policy (Miller 2005, p. 200).

I will come back to the distinction between territory and land later. For now, let us take a look at inclusionist arguments. One interpretation of these arguments begins precisely with the intuition that exclusionists have not sufficiently justified the act of enclosing borders around territories and later exclude outsiders from those territories. Arash Abizadeh defends what he calls the unbounded demos thesis: the idea that the bounded demos—-the group salienffor exclusionists - has a pre-political origin in a larger demos that encompasses humanity as a whole (2008, p. 45). The act of constituting civic borders-giving raise to groups of residents and citizens-is coercive because borders fragment the original demos invading, in a pervasive and significant way, the autonomy of would-be migrants (Abizadeh 2008, p. 37). According to liberal and democratic principles, this kind of coercion must either be removed or justified (Abizadeh 2012, p. 878). Thus, it seems that immigration controls need to be democratically justified to the very same people they intend to exclude (2008, p. 45$).{ }^{9}$ This is an attractive interpretation of inclusionism for many reasons. First, it captures a cosmopolitan challenge to exclusionism by questioning the assumption of group membership as the locus of the ethics of immigration (Carens 2013). Secondly, it binds together the interest of members and the interest of outsiders, so consideration of distributive justice among members will not outcast substantive claims of justice from nonmembers. Finally, it establishes the requirements of democratic legitimacy-a paradigmatic form of political justice-over immigration policy.

The most evident problem with Abizade's instantiation of inclusionism is its implausibility. The unbounded-demos thesis seems to require that we deem all boundaries illegitimate and that we start redrawing them from scratch. In turn, however, Abizadeh fails to provide a procedural criterion for a democratic redrawing of boundaries (Moore 2015, p. 115). This, of course, does not show that the argument is wrong in itself, but we might want to supplement this account with some idea about how to think about borders in the world that we live in. In order to face that objection, we could suggest a softer version of the unbounded-demos thesis. On this version, we waive the requirement of redrawing boundaries for the more modest indication of shifting the burden of the proof. What the soft unbounded-demos thesis points out is that exclusion is not analytically justified by popular sovereignty (a self-determining group) or by jurisdiction (an effective reasonably just state). Any exclusion should be justified by an independent argument that explains its democratic legitimacy. A corollary of this perhaps is that border policies should not be unilateral; they must give equal consideration to the interest of outsiders (Miller 2016, pp. 24-33).

Even this softer interpretation of the inbounded-demos thesis seems deeply problematic. It rests on a misleading account of coercion. What borders do to outsiders may not require democratic justification because a single action of coercion by itself is not enough to trigger demands of self-rule and distributive justice (Blake 2001; Nagel 2005; Cohen and Sabel 2006; Julius 2003; Buchanan 2002). It is necessary to be involuntarily subjected to a body of pervasive institutional coercion, such as a

9 Note that even open borders structure political jurisdictions, thereby exercising power over both insiders and outsiders by establishing different jurisdictions, for instance, in the form of their exclusive forms (policies) of regulating property and transactions. 
system of comprehensive societal norms, in order to give rise to certain relationships, such as the one established by citizenship. In contrast, what the erection of borders does to nonmembers is precisely to remove those conditions from them (Miller 2010, pp. 112-17). This conclusion may seem disappointing, but it is worth noting that something of substantive importance has been gained with the soft unbounded-demos thesis. What it establishes regarding border control is the normative requirement of justification. This means that maybe democratic legitimacy is too substantive for the case of border institutions, but this does not preclude the need for other kinds of legitimation. My three-step approach may show the path to look for that justification.

Now, recall my interpretative critical thesis about the flaws of these accounts. In Section 2, I suggested that the contradiction between requirements of justice between exclusionists and inclusionists is in part the result of the conflation between evaluations of justice and evaluations of legitimacy. Now, we can see more clearly that these approaches-rights-statism, obligations-statism, and unbounded-demos thesis - all fail to offer a justification of immigration controls grounded in an explanatory and justificatory argument that shows the normative connection between groups of citizens and residents with the land they occupy. These accounts are all inconclusive because they all fail to consider the diverse ways in which individuals and states establish associations and become associatively obligated across the land. As we will see, associations and associative obligations can be established internationally. For one, states are not only atomic associations as Wellman seems to think or isolated ethical communities as Miller thinks but also territorial entities which have seized land and which are engaged in complex relations abroad. The hope is that my three-step approach can separate these different requirements, so we can properly put the interest of members and immigrants in the same balance. ${ }^{10}$

\section{An Alternative Approach}

So far, I have focused solely on criticizing one leading approach to justice in immigration. In this section, I explain a different way of approaching the issue by reordering some of the preceding arguments to outline and motivate support for my proposal. My proposal consists of three steps. In the first stage, instead of asking what justice requires from our border institutions, I would first ask a logically prior question: what kind of border controls are legitimate; that is, at the level of our most basic moral principles, what kind of authority is permissible that borders exercise? Secondly, I ask about the nature of borders. Once we ask about legitimacy of immigration controls. it is easy to realize that borders are not only lines in the ground or the limits of our institutions but also institutions themselves. These sui generis institutions are not only domestic and, therefore, subject to standards of distributive justice for residents and citizens but also international and subject to standards of international legitimacy that should take the interest of outsiders into account. This account of borders allows to weigh together social justice and global ethics, so it may show us under what conditions it will be morally permissible for borders to prioritize the interest of residents and citizens over the interest of would-be immigrants. Thirdly, once we draw the contours of the legitimate use of border authority,

10 Note that, for exclusionists, the legitimate claim over the land is grounded in claims of distributive justice for residents and members and, even if domestic justice is a legitimate use of the land as the soft-unbounded demos thesis shows, use of land needs to be justified to outsiders. However, the unbounded demos thesis fails to provide a procedural criterion to connect political communities and land. Both accounts of exclusionism and inclusionism conflate claims of justice among members of a group — the citizenry or humanity—with legitimate claims over the land. As a result, in each case-for exclusionism and inclusionism - the focus on claims of justice is misplaced. On the one hand, inclusionism may be right when it stresses the need of justification of borders but conflates the just distribution of land with the legitimacy of democratic requirements. As a result, it also fails to engage in the discussion about the nature of borders and what is the proper relationship between borders around land, political communities, and immigrants. On the other, without an account that explains the claim that citizens and residents may have over the land and an account that analyses the nature of borders, it may be difficult to determine the limits of the priority that borders may grant to residents and citizens over the interest of potential immigrants. Exclusionism captures one important sense in which the idea of groups that protect justice is valuable: states, nations, or peoples entail value as an expression of our legitimate basic rights and as the reflection of the relations of justice we establish. 
we can again ask whether it is appropriate to distribute the right to exclude immigrants according to standards of distributive international justice by means of an international border institution.

\subsection{Step 1: The Normative Prior Question of Borders}

To analyse what would be a fair consideration of just claims of inclusion or exclusion, one has to start at the level of our most fundamental moral principles by asking what does morality require of border policy? When is it acceptable to favour the interest either of residents and citizens on one side or would-be immigrants on the other? This prior question, I believe, is the question of the legitimacy of immigration control.

Step 1 follows from a number of arguments and ideas I invoked before. Rights-statism and obligations-statism showed us that political communities have a right to control and administrate admissions even though that right does not translate into a right for exclusion. Soft unbounded-demos thesis stressed that that kind of control needs to be nonetheless justified. Now, we can ask the following: When does the case of borders require evaluations of legitimacy rather than evaluations of justice? Under what criteria do certain circumstances require the virtue of legitimacy? An influential account of legitimacy is offered by Bernard Williams. This account begins with the assumption that de facto effective power is not enough to justify authority. To ask about the moral quality of authority is to assess if those who claim authority are in some way justified to do so. Do their claims of authority make any sense to those subjected to it? Will I be morally wrong if I choose to challenge that authority? How could authority ever make sense if authority clashes with everyone's nature as free and equal individuals? The answer to this kind of questions lies in the establishment of a regime that secures the stability of some order for protection, safety, trust, and cooperation (Williams 2005, p. 3). Authority is justified or legitimate when it makes sense as a sort of plausible and credible solution to this problem of politics.

Now, according to Williams, we can distinguish meeting this requirement for justification from meeting other political virtues such as distributive justice or political justice even if sometimes these requirements overlap with each other (Williams 2005, p. 4). For instance, it is of course possible, as in the case of the domestic basic structure of a liberal society that the most plausible way of meeting the demands of justification, is to appeal to political justice, fairness, or distributive justice. However, the same circumstances arise in which the only way to justify political power is to avoid reference to liberal political virtues or at least a justification could be coherently articulated in an attractive way without reference to such virtues. For instance, when a social group has been historically discriminated against and excluded from wealth and opportunities, it may be deeply unjust for applicants for a job with merits to be dismissed in favour of reparative quotas. However, the legitimacy of social and political institutions needs to be re-established for members of the discriminated social group if social institutions are to exercise political power over them without harming their dignity even if this means to unjustly deprive some applicants from the dominant group from opportunities they deserve. If instead we avoid reference to standards of legitimacy, we have to face the unpalatable conclusion that giving the job to any of them is both just and unjust at the same time.

To be sure, the connection between authority and legitimacy is often posed too as a dilemma of justification. Legitimate authority is the best chance human beings have for the protection of their most basic rights, but at the same time and almost for the very same reasons, the establishment of authority is the worst threat to the protection of those rights (Williams 2005; Dworkin 2013). This means that legitimacy is not a closed evaluation or adjudication. Instead, we need to continuously assess the legitimacy of institutions because the very same institutions that, at some point, are part of the solution (of a given institutional problem) may easily turn into part of the problem they are supposed to fix in the first place. All things being equal, it is claimed that the authority that immigration controls exercise is needed to protect the basic rights of residents and citizens, but at the same time, immigration controls could easily threaten those very same rights. For instance, immigrants may depredate government services without proportionate contribution in taxes (Freiman and Hidalgo 2016, p. 12), but at the same 
time, immigration controls may illegitimately curtail the freedom of association of citizens who want to share the house with foreign nationals (Steiner 2018, p. 140).

Now, we may raise an alternative normative start: We beguine by distinguishing concerns of legitimacy and concerns of justice. If the general problem of borders is to determine what kind of borders liberal democracies ought to have or, rather, what morality requires from border controls, then this raises two particular problems: first, to justify the exclusive control over the administration of borders (the problem of legitimacy of borders) and, second, to specify how this control ought to be exercised (the problem of justice of borders). Once we divide these levels of analysis like this, we may see how it makes sense to understand borders as sui generis institutions domestic and international: we can distinguish between the institutional entitlement to exercise dominion over borders internationally from the way this entitlement is exercised here at home. In general, while an illegitimate state is not entitled to exercise any border control, a legitimate state may exercise many kinds of border control that we can assess according to justice. ${ }^{11}$ However, how do we know that, for the case of immigration controls, the requirements for justification are different from the requirements of other political virtues such as justice? In order to determine, that we must turn to the nature of borders.

\subsection{Step 2: A New Normative Conception of Borders}

Political theory often misrepresents international borders because it takes them into account merely as lines on the ground or as the outer limit of domestic institutions marking out jurisdictional boundaries. This certainly makes sense from the point of view of exclusionism and political justice because borders will serve only the purpose to contain the inner institutions and to keep everything else out as the state or the community sees it fit. However, as we saw following soft unbounded-demos thesis, immigration controls are an exercise of power that needs to be justified and borders are institutions that carry on that exercise. If this is true, then borders are not jurisdictional limits but institutions themselves. Therefore, we can ask about the institutional requisite function of borders and pick up from there what borders should be according to those requisite functions. The requisite function of borders is conventionally to administer the flow of people and goods from one state to the other (Barry and Goodin 1992, p. 6), but for the case of complex liberal democracies, this entails not only customs and immigration offices but also airports, sea ports, mail offices, embassies, consulates, international affairs bureaus, etc. ${ }^{12}$ This means that, in order to fulfil their requisite functions, borders have become over the past 100 years a highly complex and specialized set of institutions devoted precisely to administering the territorial, institutional, and populational limits between states (Camacho 2016).

However, this is not enough to understand the nature of borders. A good description about international relations should tell us not only something about the institutional nature of states as units but also something else about the institutional nature of the international system as a whole (Waltz [1979] 2010). This means that, from an institutional and international perspective, borders are not only institutions of the state but also international institutions. We can in fact distinguish borders from the rest of the institutions of the state because borders, as opposed to basic institutions-such as the executive or the judiciary - are the kind of institutions that exercise political power systematically over both insiders and outsiders. As such, borders are sui generis institutions because they are at the same time domestic, for instance, when they issue passports or let in imports, and international, for instance, in the case of consulates and embassies, when they administrate the relationships between neighbouring countries. Note that this would mean that borders not only administrate the flow of people but also administrate other aspects of international relations such as the flow of commodities, currencies, and services and perhaps also cultures, languages, influence, and other intangible goods.

11 Legitimacy is a piecemeal evaluation. Once this account develops further, it should take into account matters of degree, but for simplicity, I focus in the general case.

12 See (Valenzuela and Camacho). 
From a systematic institutional perspective, in order to perform their requisite functions, borders of one country should interact with the borders of other countries, in fact intertwining in a net or system of border institutions regionally and, in the case of affluent liberal democracies, even globally. The more exchange and flow border institutions need to administrate, the more globally interconnected borders are with border institutions of other countries. This kind of complexity also implies that borders are not a unique institution. Not even international border tolls are part of the same institution. Different border institutions are created depending on with what country a relationship has been established. For instance, Spanish border institutions with Morocco are different from Spanish border institutions with France precisely because border institutions with Morocco reflect the uniqueness of the relationship with these two countries. This also means that two countries do not need to be neighbours to have a border. When I board a plane and descend in Frankfurt, I am subjected to the immigration considerations Germany has established for Mexicans, and this amounts to being subjected to the authority of the German-Mexican border institution even if this border is somehow virtual.

The last century has seen a fast development of border institutions, turning them into a well-established global set of rules and offices that have established a basic institutional structure all around the globe. The exact character of this system though is unclear. It obviously is not analogous to the domestic basic structure of liberal democracies, but we know that at least this system makes international cooperation possible and that sometimes it is permeable to moral reasons such as those contained in the doctrine of human rights. In fact, there is a chance that just and legitimate borders administrate a great deal of what we call international relations. Under my account, perhaps even public affairs bureaus may be considered part of border institutions. I will say a bit more about the normative nature of borders in the next section. For now, it is important to come back to the problem of legitimacy.

According to this account, borders are a system of international complex pluralistic institutions that acquire their special identity from the specific relationship they embody. There are at least two sources of legitimacy coherent with this account: the relationship that gives them identity and the claims over the land they enclose. First, borders are legitimate when they perform their requisite functions, and under this account, that means that a specific border (between two given countries) is legitimate when its policy (including but not limited to immigration policy) reflects the actual relationship between these two given countries. For instance, this means that, if these two countries have an intensive relationship in terms of cultural, commercial, and diplomatic exchange and one of the two countries excludes citizens and residents of the other in a way that does not make sense according to that relationship, then the exclusionary policy is illegitimate in a way that devaluates the legitimacy of the border institution that sustains it.

Second, as we saw in Section 3, exclusionary policy needs to be grounded in a legitimate claim over the land. If a country does not have a legitimate claim over the land it occupies, then it is difficult to see how or to what extent their borders can be legitimate. In order to perform the exclusion of would-be immigrants legitimately, borders must logically presuppose a previous source of legitimacy: the legitimate authority, legitimate dominion, or monopolistic control over the land in a way that both jurisdiction and dominion coincide with the borders. Rights to establish borders need to include the right to establish a jurisdiction and the right to occupy that land for the purpose of establishing political communities with the power to exclude would-be immigrants. Jurisdiction alone cannot justify exclusionary rights. Many accounts argue since Kant that a political community gains rights over the territory as it manages to create and sustain legitimate and just institutions (Moore 2015; Ypi 2013; Stilz 2011; Simmons 2001). However, what is under review is the right of that community to establish those institutions there in the first place. I will also come back to this problem in the last section. 


\subsection{Step 3: Just Exclusions}

Once we make sure borders may exercise their immigration authority legitimately, we need to assess their policies according to standards of justice. As we saw in the last section, this assessment cannot be constructed only from the point of view of domestic social justice. Of course, borders protect the interests and rights of citizens and residents, but as my analysis of exclusionist accounts reveal, evaluations of domestic social justice do not exhaust the morality of borders and immigration controls. One suggestion to balance claims of global justice with claims of domestic social justice within international legitimacy is the creation of an institution capable of distributing rights of exclusion for local border institutions.

Javier Hidalgo notes that states' decisions regarding immigration restrictions may be morally questionable (Hidalgo 2013) and sometimes harmful (Hidalgo 2016, pp. 153-54). If this is true, Hidalgo argues that states may have moral reasons to transfer at least some of their decision-making authority over immigration to international immigration institutions. States should join a world migration organization that establishes an institutional multilateral framework for negotiating migration flows between states (Hidalgo 2016; Bhagwati 2003). Note that the existence of such a World Migration Organization transforms again the problem of exclusion of would-be immigrants into a distributive problem. Is this sound?

Hidalgo's proposal is problematic in terms of international legitimacy as there are very weak incentives for the creation and continuation of an organization of this kind (Hidalgo 2016, pp. 148-50). One reason is that policy makers have negative incentives coming from local voters. Often, it is easier for irresponsible or short-sighted politicians to blame last comers about social problems, and at the same time, voters often prefer to form false beliefs and to blame immigrants for social problems even if in both cases they lack any convincing evidence to do so. ${ }^{13}$ Secondly, the benefits from relaxing immigration controls tend to favour worse-off countries instead of rich ones, at least in the short term.

Note that, under my normative account, borders are understood already as a system of domestic and international institutions. Once border institutions fulfill not only the demands of domestic social justice but also those of international legitimacy, the states with legitimate borders may find reason to establish institutional forms of international cooperation regarding borders and immigration policy. To be sure, the requisite function of border institutions-here and now-already is to administrate and control the flow of people and goods and, in doing so, to a great extent to administrate the relationship between countries. When one country establishes trade, diplomatic, or other kind of relations with others, it means (i) that their societies acquire certain moral obligations determined by the strength of the relationship and (ii) that these obligations may give rise to special institutional requirements by means of consent in the form of agreements or treaties between these two countries. Therefore, border institutions gain legitimacy when they reflect the particular relationship between countries in terms of consented duties, associative duties, and the character of the relationship as a whole. However, border policy unfolds not only in bilateral forms. When states need to administrate the border institutions and immigration controls of a group of countries in cooperative terms, it will make sense to coordinate that effort in an institutional fashion.

Suppose a cluster of liberal democracies establish a legitimate system of borders that reflects accurately their consented and associative obligations. Then, it may be plausible that they decide to disincentivize defectors by organizing their system of borders under a centralized institution such as the one described by Hidalgo. This, of course, changes the nature of the problem of immigration controls back to the kind of problem that can be assessed by a conception of distributive justice, but it does this in a way that the distribution of exclusionary rights may be just because it is the result of a

13 For the claim that majorities often blame immigrants for social problems without empirical evidence, see (Miller 2009, p. 36). For the claim that blaming immigrants for social problems is often wrong, see (Fromentin 2013). Cited in (Hidalgo 2016, p. 149). 
legitimate use of institutional authority when this authority comes from a legitimate system of borders. The problem arises because, in reality, we know that, seldom, immigration restrictions embody the associative obligations established by the actual interaction between two countries. ${ }^{14}$ For instance, in North America, Canada, the USA, and México have been engaged in deep trade and cultural and diplomatic relations, yet immigration restrictions do not necessarily reflect the level of engagement, cooperation, and interdependence between these three states.

\section{International Legitimacy and the Legitimacy of Borders}

These sections complete my outline. The account here does, of course, need to be developed further. Most obviously, as I said in the introduction, my account of borders and the legitimate claims over the land needs to be given substantive content. As a result, steps 2 and 3 can only be endorsed in a provisional sense. When applying the approach outlined above, one must be careful to not simply move from the fact that borders already exercise power in certain ways to the conclusion that those instances of international power are justified. However, despite this, there are two important objections to my approach. First, it could be argued that the distinction between justice and legitimacy is trivial or at least not informative. What I call legitimacy can be properly described as a form of justice. Second, international legitimacy of borders has little or nothing to do with immigration policy. Typically, we do not assess the legitimacy of borders of other states based on the immigration policy as a criterion. ${ }^{15}$

Let us consider first the conceptual analysis objection. It could be argued that the distributive claims of international ethics (claims between states) may be reducible to the distributive claim of global justice (claims between all individuals), making my account trivial. ${ }^{16}$ Sometimes, the distinction between different things we call justice may be a mere linguistic or terminological disagreement between a core understanding of justice and some penumbra controversial cases in very much the same way that astronomers discuss whether it is appropriate to use the concept of planet for the case of Pluto (Dworkin 2013, p. 5). For instance, we can agree or disagree whether family is an appropriate object of distributive justice. Some thought that family was too private to be considered an object of social justice, and some others thought that family was the source of many social injustices we ought to consider publicly. ${ }^{17}$ However, that discussion did not involve picking up one concept or conception of justice over other alternatives; instead, the discussion needed to clarify whether a shared conception of justice applied to a controversial case such as family. Now, some will be tempted to suggest that the distinction I am proposing between concerns of legitimacy and concerns of justice in the international realm is merely terminological. They will insist that we can agree or disagree about the question of whether it would be appropriate for theoretical and applied purposes to include global justice within

14 Under the complex account of borders, associative obligations tend to be multilateral because the normative evaluation is comparative. The border of one country establishes interactions with several other borders, and the nature of these interactions could be assessed in comparative terms. Consider an example. There are three democracies in the north part of one continent. $\mathrm{C}, \mathrm{U}$, and $\mathrm{M}$ are engaged in a strong and deep relationship with each other; they have established terms for free trade and deep diplomatic and cultural relations. They are also engaged in institutional cooperation regarding key subjects such as security, development, and administration. As a result, they plan and design together their institutions and policies. Country $\mathrm{U}$ treats $\mathrm{C}$ as its partner, thus administrating border institutions relative to $\mathrm{C}$ accordingly. $\mathrm{U}$ welcomes $C^{\prime}$ s nationals and their foreign affairs offices, and other institutions exercise political power in order to accommodate the close relationship with $C$, yet $U$ treats $M$ in a different way. U does not welcome $\mathrm{M}^{\prime}$ s nationals and also places other kinds of restrictions on the rest of M's border institutions. Overall, $\mathrm{U}$ treats $\mathrm{C}$ as a friend and partner and $\mathrm{M}$ as a subordinate. According to the complex account of borders, $\mathrm{U}$ wrongs $\mathrm{M}$ and its habitants because it has established a relationship with $\mathrm{M}$ that has moral character, and as such, it entails certain obligations. U has grown into a complex and deep relationship with both $\mathrm{C}$ and $\mathrm{M}$. This deep relationship creates associative responsibilities that are not exhausted by consent, yet $\mathrm{U}$ only consents to acknowledging those obligations for the case of $\mathrm{C}$. The lack of explicit consent in the case of $\mathrm{M}$, however, does not cancel the associative obligations that $U$ has acquired with $M$ through its practices. When $U$ engages in a deep and complex relationship with $M$ yet decides to exclude $\mathrm{M}^{\prime}$ s nationals, it undermines the ground of legitimacy insofar as it exploits and subjects M's nationals by benefiting from a relationship with them but mistreating them at the same time.

15 I am in debt to an anonymous reviser who suggested to me this objection.

16 I am grateful to an anonymous reader that raised this objection.

17 See (Young 1990) for discussion. 
the more general conception of distributive justice, but in the end, that is a terminological query about a controversial instance. I believe the distinction I am stressing is not merely terminological.

I follow Dworkin when I reject that all the conceptual disagreements of this kind are always criterial or semantic. There are certain problems that require an interpretative approach such as determining what morality requires in certain circumstances characterized by the lack of special relationships or relationships of partiality. In this case, inclusionists have assumed that immigration problems require accounts of global justice that establish claims between individuals from different political communities because there is no global community. However, this simply neglects the fact that borders are intergovernmental institutions that potentially could establish forms of international governance over immigration restrictions. This kind of institutions and the governance they will produce in the close future will constrain in turn the claims of global justice that immigrants residents and citizens could press against each other.

If my interpretative thesis is sound, the tension between exclusionists and inclusionists is not merely semantic. Exclusionists take justice as an evaluative concern by asking what normative conclusions we can extrapolate about immigration considering how immigration policy is conventionally understood as largely discretionary. In contrast, inclusionists take justice as determining whether any immigration control is right or wrong. For defenders of exclusionism, justice is a remedial virtue of institutions here and now, and for defenders of inclusionism, justice is a context-independent value about what is right. In contrast, interpretative moral questions such as who gets to decide whether two persons from different nationalities who love each other could live together in the same place or what is the limit of immigration authority regarding the movement of highly qualified people cannot be answered by discussing the scope of justice in a semantic way. For such a question, we need an interpretative dynamic account that allows the division of labour between different levels of analysis in order to determine first what kind of uses of political power are morally permissible for borders and later what legitimate uses of immigration authority are just. My three-step approach offers at least three layers of analysis that supplements the standard account. The standard account assesses immigration policy according to the interests of some residents and citizens only, but under the three-step approach, that assessment needs to be weighed against the international legitimacy of border institutions.

The second objection however stresses that typically international legitimacy has little or nothing to do with immigration policy. ${ }^{18}$ We know this is true because the legitimacy of borders is more obviously linked with territorial disputes. The moment borders cease to be accepted by the consent of parties, there are important consequences. Conflict arises (armed, diplomatic, or otherwise) as was the case in the Atacama region between Perú, Chile, and Bolivia. Recently, Bolivian president Evo Morales decided to break the border treaties signed by both countries. He filed a case with the International Court of Justice on 24 April 2013, but the international court, following the principle of uti possidetis, did not change the borders formerly established by the previous treaty. However, it is not clear what would be the implications of my approach regarding noncompliance and "illegitimate border authority". As I said before at the beginning of this section, my account of the legitimacy of borders needs to be developed further. For now, the consequences are merely normative. ${ }^{19}$ For instance, it is important to note two important things about territorial legitimacy. First, territorial legitimacy is not alien or unrelated to immigration controls. It is quite the opposite, as we saw; if my critical objection is sound, the possibility of grounding legitimate exclusionist immigration controls depends, to a certain extent, on the possibility of establishing a certain form of legitimate dominion or moral claim over the land. Second, the complex account of borders I am proposing is neither prescriptive nor descriptive. It is normative in a realistic fashion. It captures some features and good practices of borders of liberal democracies and offers an interpretation of their functions that is in accordance with our moral claims

18 I am in debt to an anonymous reviewer for raising this objection.

19 Many thanks to an anonymous reviewer for pressing me on this. 
and principles. Therefore, the fact that the legitimacy of borders has here and now little to do with the legitimacy of immigration controls is not necessarily an objection if the interpretative account shows that immigration controls and legitimacy of borders should be connected.

Note that this shows a shift in the approach. Previously, discussing assessments of justice and legitimacy, I have proceeded by means of conceptual analysis to try to find the most coherent way to make sense of claims, concerns, and standards regarding exclusion of would-be immigrants. With my account of borders, I sought to think about border institutions as they are here and now according to an interpretation of their best traits and practices as if we were going from the ground up. The hope is that the approach from legitimacy of borders serves to outline an alternative way of thinking about rights to exclude would-be immigrants. ${ }^{20}$

One example of this realistic normative approach is precisely the untheorized relationship between political communities, institutions - in this case, borders-and the land. As a matter of fact, we currently lack a good explanation of how borders can legitimately seize a part of the earth, yet we continue with the normative account of borders in the hope that we can find good reasons to understand claims over the land that are coherent with our concerns about legitimacy and justice. This needs to be unpacked.

One influential view holds that peoples may hold legitimate control over territories when they demonstrate they have legitimate and just manifestations of political self-determination. Peoples are communities that share a distinct political identity which derives from a collective mobilization for creating and maintaining legitimate institutions of justice. In contrast with nations that are sustained and protected by the power of the state, political identity is sustained organically by the characteristically social mobilization and agency that peoples have in contrast with other groups and other forms of collective control (Moore 2015, p. 50). According to Margaret Moore, borders should be drawn around groups that meet the criteria of legitimate peoplehood because peoplehood generates a right of occupation of the land. These heartlands generate a qualified and pro tanto right to control borders, including the power to exclude potential migrants, justified as an extension of jurisdictional authority and (like jurisdictional authority) in terms of the moral value of collective self-determination. ${ }^{21}$

The problem with this account is that it misrepresents the kind of political relationships that seem more important in contemporary liberal democracies by attributing jurisdictional rights to peoples instead of acknowledging that, in the conditions familiar to us, states are the only agents establishing jurisdictions. Of course, Moore could answer that her work is also a normative account of territory, but her account also begs the normative question because what we are challenging is precisely the entitlement over the land, including all territorial rights such as jurisdiction. In order to see this, three distinctions should be in place. First, following Moore, we can distinguish states from peoples and we know that we have more peoples than states, so presumably, there are several peoples inside a single state. Second, Moore also accepts the distinction between rights over the land and territorial rights. Land is all the surface not covered with water, while territories are social constructs. Typically, property rights are applied to land while jurisdiction is a territorial right. Finally, we can distinguish legal rights from moral rights. Any jurisdiction establishes the validity over a territory of several legal rights and legal rules, while moral rights are stablished by status or by certain basic human interests in the sense that they apply to all jurisdictions.

Now, note that, when she attributes to peoples the capacity to establish jurisdiction, this leaves unanswered the question of how peoples acquire the right to reject outsiders while only establishing that peoples acquire the right to impose valid law over a territory. We know this because jurisdictions tend to be inclusive rather than exclusive. For instance, when an immigrant crosses the border

20 About this kind of approach, see (Walzer 1983, chp. II); “Membership” and, more recently, (Carens 2013, pp. 8-13).

21 Of course, the resultant exclusionary rights are qualified rights because they have to be pursued in ways consistent with basic human rights, for instance, by being accompanied by policies that address serious deprivation in those parts of the world which we typically think of as "migrant-sending societies". 
without permission, we do not assume that they are legally or morally permitted to rob banks or to seize property insofar as we believe that regardless of their migratory status, they are subject to our jurisdiction. Of course, we could argue that, in our jurisdiction, there is a law that says "non-citizens must be kept out until a permission to come is given to them", but this does not solve the normative challenge since what is under scrutiny here is the moral right of states or any political agent to establish and enforce those kinds of rules. Furthermore, Moore's manoeuvre has very unpalatable consequences. Suppose we accept that peoples have territorial rights and Yucatecos (inhabitants of the state of Yucatan) in Mexico qualify as a people following Moore's characterization. One day, they wish to resist Chilangos (inhabitants of México city) from moving to their beautiful city of Mérida and they change the law in order to prohibit the immigration of Chilangos. Under what grounds can we challenge that? Coherence with Moore's rationale will suggest that we could not, and if Yucatecos are serious about their rejection of Chilangos, they will have a qualified pro tanto right to resist their immigration tendencies as much as mobilized groups can resist gentrification. Therefore, it will be very difficult to explain how exclusionary rights could be transferred or administrated by the state, as dissenters could always challenge states' authority over immigration laws.

It seems that the legitimacy of immigration controls is, after all, necessarily connected with the international legitimacy of borders. Moore's basic right of occupation explains the need for certain space and jurisdiction, but it cannot justify current borders because it only identifies peoples' heartlands. The lack of capacity to normatively draw borders results in a lack of grounds for exclusion of would-be immigrants. After all, as we saw, land, as opposed to jurisdiction, is not an idea, a system of rules, or a social construction. Land is a scarce resource that not only allows opportunities for physical survival, for instance, when we farm it or build refuge from the elements, but also makes possible opportunities for organization that develop collective valuable forms of discharging individual duties and institutional mutual care. However, it is not clear what reasons could be invoked for excluding would-be immigrants from it, particularly when these immigrants wish to cooperate in the production of such goods.

\section{Conclusions}

Nothing that I have said here implies that the core intuition behind inclusionism is untrue or conceptually incoherent. Defenders of inclusionism must realize that both exclusionism and inclusionism constitute efforts to make sense of claims of political justice. ${ }^{22}$ Exclusionism focuses mostly on the problem of justice for members and leaves the problem of the legitimacy of immigration controls (justification of land and land-control) completely underdetermined. Inclusionism, on the other hand, turns the problem on its head: whereas exclusionism tries to determine what justice requires from border restrictions, inclusionism seeks to determine what kind of political justice is required for a world without borders that requires the distribution of land and the redrawing of borders. While inclusionism points to political arrangements that are yet to be envisioned, exclusionism works under the assumption that states are the only agents capable of playing this role in any meaningful way. Exclusionism also assumes that states are legitimate when they are able to establish relationships of justice among members, but inclusionism shows that states' legitimacy is incomplete unless it acquires legitimacy beyond borders. But both assume without argument what is being challenged: the legitimacy or illegitimacy of exclusion from the land administrated by immigration institutions that are both local and international.

22 As we saw, this means that exclusionism and inclusionism are different conceptions of justice in immigration, but I assume both have a good idea about a concept of justice they want to satisfy. Exclusionism seems to be mainly concerned about how to satisfy the substantive claims of citizens, while inclusionism seems to be mainly concerned about which political arrangements may satisfy the substantive claims of everyone. About the difference between concept and conceptions of justice, see (Rawls 2001a, p. 5). For concepts of justice, see (Cohen 2009, p. 279). 
To be clear, I do not categorically reject exclusionist's or inclusionist's core concerns about justice. Instead, I insist that the way they frame their claims of justice tends to simply assume what we must justify: the kind of legitimate institutional control over the land (borders) and the land itself that makes normatively possible justifying the exclusion of would-be immigrants. Therefore, my suggestion is to take a step back from the traditional understanding of political justice and to assess separately the different normative requirements that pose the problem of immigration controls and policy. I have suggested to take this in three stages.

First, we appeal to the conceptual difference between legitimacy and justice even if justice contains democratic legitimacy of some sort. This is because, in the second stage, we appeal to the sui generis nature of borders as domestic and international complex institutions. From the domestic point of view, borders should accommodate requirements of justice, even political justice, but from outside, borders should coincide with requirements of international legitimacy. In a nutshell, the requirements of political theory and the theory of international relations must appear to be coherent for the case of border controls. My account at the third stage then establishes an institutional mechanism to connect exclusionist's claims of justice for the interest of citizens and residents with inclusionist's project of global emancipation and equality. Exclusionary rights may instead be distributed by an international or global institution of some sort according to standards of global justice.

However, I leave unsolved the problem of legitimate claims over the land, and under my account, the legitimacy of borders, to a certain extent, rely on this other kind of legitimacy over a physical resource such as the earth. Perhaps Kantians are right when they claim that only when a just system of international relations has been constructed may states claim that kind of right grounding as a result their exclusionary claims. Be that as it may, I believe it is somehow explanatory to be sure about the possible sources of exclusionary rights. They should come from a normative explanation of borders sensible to ethical considerations in international relations and from claims over the land when used for establishing relationships that allow us to discharge our moral obligations and to find our rights protected by others. I leave this last problem for another paper.

Funding: This research was funded by the Nacional System of Researchers (Conacyt Mexico) Level 1. Also, this research has been funded by Universidad Panamericana through the grant "Fomento a la Investigación UP 2017", under project code UP-CI-2017-FIL-MX-01.

Acknowledgments: I am indebted to the audiences of "Migration and Territory" seminar sessions, particularly with Luis Xavier López Farjeat, Cecilia Coronado, Sandra Anchondo, Alfonso Ganem, José Luis Rivera, and Fabiola Saul. A previous version of this paper benefited from audiences at the Workshop on Migration and Territory during May 2018 at Panamericana University. On that occasion, comments from Margaret Moore, Christine Straehle, Arash Abizadeh, Bernardo Bolaños, and Moisés Vaca were particularly useful for framing the concerns of this paper. A very early version of this paper has also benefitted from audiences at the MANCEPT seminar at Manchester Uni during the fall of 2015. I am grateful to Miriam Ronzoni and Richard Child for their objections and to Liam Shields for his warm support. I benefited as well from comments given to this paper at the POLEMO seminar at CEU Hungary as well during 2015. Many thanks to Eszter Kollar, Andres Moles, and Zoltan Miklosi for their comments. Also, I have to mention that numerous undergraduate and graduate students have contributed during modelled-seminar sessions. I am particularly grateful to Students of philosophy at Panamericana during spring 2019; specially Carlos Noyola, Juan Diego Maya and Nadia Munguía for their insightful objections. I thank students of International Relations at Ibero during Spring 2018, students of MA in history of the Thought at Panamericana University during Fall 2018 and Students of Philosophy of History and Social Sciences at UNAM during semester 2019-1, particularly Sebastián Tinajero, Elvia Ruiz, and Erick Nava for their enthusiastic rejoinders. Many thanks to Ernesto Castañeda and three anonymous reviewers for their profound, highly specific, and very generous critics and comments. Finally, I thank Aidan Barlow for his diligent efforts to make this work readable in English.

Conflicts of Interest: The author declares no conflict of interest.

\section{References}

Abizadeh, Arash. 2008. Democratic Theory and Border Coercion: No Right to Unilaterally Control Your Own Borders. Political Theory 36: 37-65. [CrossRef]

Abizadeh, Arash. 2012. On the Demos and Its Kin: Nationalism, Democracy and the Boundary Problem. American Political Science Review 106: 867-82. [CrossRef] 
Barry, Brian. 1991. Liberty and Justice: Essays in Political Theory 2. Oxford: Clarendon Press, vol. 2.

Barry, Brian, and Robert E. Goodin, eds. 1992. Free Movement. London: Routledge.

Beitz, Charles R. 2011. The Idea of Human Rights. Oxford: Oxford University Press.

Bhagwati, Jagdish. 2003. Borders Beyond Control. Foreign Affairs 82: 98-104. [CrossRef]

Blake, Michael. 2001. Distributive Justice, State Coercion and Autonomy. Philosophy and Public Affairs 30: $257-96$.

[CrossRef]

Blake, Michael, and Risse Mathias. 2008. Immigration and Political Equality. San Diego Law Review 45: $963-85$.

Buchanan, Allen. 2002. Political legitimacy and democracy. Ethics 112: 689-719. [CrossRef]

Camacho, Enrique. 2016. The Moral Character of Immigration Controls. Migración= Migration= Migração. Vila Real: Universida de Santiago de Compostela, Instituto Internacional Casa de Mateus, pp. 19-40.

Camacho, Enrique. 2017. Nationalism and crisis. Tópicos 52: 427-54. [CrossRef]

Carens, Joseph H. 1987. Aliens and citizens: the case for open borders. The Review of Politics 49: 251-73. [CrossRef]

Carens, Joseph. 2013. The Ethics of Immigration. Oxford: Oxford University Press.

Castañeda, Ernesto, and Cathy L. Schneider, eds. 2017. Collective Violence, Contentious Politics, and Social Change: A Charles Tilly Reader. New York: Taylor \& Francis.

Cohen, Joshua. 2004. Minimalism about human rights: The most we can hope for? Journal of Political Philosophy 11: 190-213. [CrossRef]

Cohen, Gerald. A. 2009. Rescuing Justice and Equality. Cambridge: Harvard University Press.

Cohen, Joshua, and Charles Sabel. 2006. Extra rempublicam nulla justitia? Philosophy E Public Affairs 34: 147-75.

Dworkin, Ronald. 2013. A new philosophy for international law. Philosophy \& Public Affairs 41: 2-30.

Fine, Sarah. 2010. Freedom of Association Is Not the Answer. Ethics 120: 338-56. [CrossRef]

Fine, Sarah, and Andrea Sangiovanni. 2015. Immigration. In The Routledge Handbook of Global Ethics. Edited by Darrel Moellendorf and Heather Widdows. London: Routledge, pp. 193-209.

Freiman, Christopher, and Javier Hidalgo. 2016. Liberalism or immigration restrictions, but not both. Journal of Ethics E Social Philosophy 10: 1.

Fromentin, Vincent. 2013. The Relationship Between Immigration and Unemployment: The Case of France. Economic Policy \& Analysis 43: 51-66.

Gans, Chaim. 1998. Nationalism and Immigration. Ethical Theory and Moral Practice 1: 159-80. [CrossRef]

Hidalgo, Javier. 2012. Self-determination, immigration restrictions, and the problem of compatriot deportation. Journal of International Political Theory 10: 261-82. [CrossRef]

Hidalgo, Javier. 2013. Associative Duties and Immigration. Journal of Moral Philosophy 10: 697-722. [CrossRef]

Hidalgo, Javier. 2016. The case for the international governance of immigration. International Theory 8: 140-70. [CrossRef]

Hobbes, Thomas. 1968. Leviathan. Edited by Crawford Brough Mcpherson. Harmondsworth: Penguin.

Julius, Alexander. J. 2003. Basic structure and the value of equality. Philosophy \& Public Affairs 31: 321-55.

Kant, Immanuel. 1991. Practical Philosophy. Edited by Mary J. Gregor. Cambridge: Cambridge University Press. First published 1781.

Kukathas, Chandran. 2005. The case for open immigration. In Contemporary Debates in Applied Ethics. Edited by Andrew Cohen and Christopher H. Wellman. New Jersey: Wiley-Blackwell, pp. 207-20.

Locke, John. 1988. Two Treatises of Government. Edited by Peter Laslett. Cambridge: Cambridge University Press. First published 1689.

Macedo, Stephen. 2018. The Moral Dilemma of U.S. Immigration Policy Revisited: Open Borders vs. Social Justice? In Debating Immigration. Edited by Carol Swain. Cambridge: Cambridge University Press, pp. 286-310.

Miller, David. 1995. On Nationality. Oxford: Clarendon Press.

Miller, David. 2005. Immigration: The Case of Limits. In Contemporary Debates of Applied Ethics. Edited by Andrew Cohen and Christopher Heath Wellman. New York: Wiley-Blackwell.

Miller, David. 2007. National Responsibility and Global Justice. Oxford: Oxford University Press.

Miller, Stephen. 2009. Economic Bias and Ideology. Journal of Private Enterprise 25: 31-49.

Miller, David. 2010. Why immigration controls are not coercive: A reply to Arash Abizadeh. Political Theory 33: 111-20. [CrossRef]

Miller, David. 2016. Strangers in Our Midst. Harvard: Harvard University Press.

Moore, Margaret. 2015. A Political Theory of Territory. Oxford: Oxford University Press.

Nagel, Thomas. 2005. The problem of global justice. Philosophy E Public Affairs 33: 113-47. 
Peter, Fabienne. 2009. Democratic Legitimacy. London: Routledge.

Quong, Jonathan. 2011. Liberalism without Perfection. Oxford: Oxford University Press.

Rawls, John. 1971. A Theory of Justice. Cambridge: Harvard University Press.

Rawls, John. 2001a. The Law of Peoples: With "The Idea of Public Reason Revisited". Harvard: Harvard University Press.

Rawls, John. 2001b. Justice as Fairness: A Restatement. Harvard: Harvard University Press.

Rossi, Enzo. 2014. Legitimacy and consensus in Rawls' political liberalism. Iride 27: 37-56.

Scanlon, Thomas. 1998. What We Owe to Each Other. Cambridge: Harvard University Press.

Scheffler, Samuel. 2002. Boundaries and Allegiances: Problems of Justice and Responsibility in Liberal Thought. Oxford: Oxford University Press.

Simmons, A. John. 1999. Justification and legitimacy. Ethics 109: 739-71. [CrossRef]

Simmons, John. 2001. On the Territorial Right of States. Philosophical Issues: Social, Political and Legal Philosophy 11: 300-26. [CrossRef]

Sleat, Matt. 2015. Justice and Legitimacy in Contemporary Liberal Thought: A Critque. Social Theory and Practice 41: 230-52. [CrossRef]

Song, Edward. 2012. Rawls's liberal principle of legitimacy. The Philosophical Forum Quarterly 43: 153-73. [CrossRef]

Steiner, Hillel. 2018. Territorial justice. In National Rights, International Obligations. Edited by Simon Caney. London: Routledge, pp. 139-48.

Stilz, Anna. 2011. Nations, States and Territory. Ethics 121: 572-601. [CrossRef]

Tamir, Yael. 1993. Liberal Nationalism. Princeton: Princeton University Press.

Valentini, Laura. 2012. Assessing the global order: justice, legitimacy, or political justice? Critical Review of International Social and Political Philosophy 15: 593-612. [CrossRef]

Valenzuela, K., and E. Camacho. Forthcoming. ¿Más o Mejor? El Caso de los Trabajadores Temporales y la Protección Consular Mexicana en Canadá. In Una Revisión Crítica del Paradigma de los Derechos Humanos en la Modernidad Tardía. Edited by Mario Hernández.

Van der Vossen, Bas. 2015. Immigration and self-determination. Politics, Philosophy E Economics 14: 270-90.

Waltz, Kenneth. N. 2010. Theory of International Politics. Tennessee: Waveland Press. First published 1979.

Walzer, Michael. 1983. Spheres of Justice. Oxford: Basil Blackwell.

Wellman, Christopher Heath. 2008. Immigration and Freedom of Association. Ethics 119: 109-41. [CrossRef]

Wellman, Christopher Heath, and Phillip Cole. 2011. Debating the Ethics of Immigration: Is There a Right to Exclude? New York: Oxford University Press.

Williams, A. O. Bernard. 2005. In the Beginning Was the Deed: Realism and Moralism in Political Argument. Princeton: Princeton University Press.

Young, Iris. 1990. Justice and the Politics of Difference. Princeton: Princeton University Press.

Ypi, Lea. 2013. A Permissive Theory of Territorial Rights. European Journal of Philosophy 21. [CrossRef]

(C) 2019 by the author. Licensee MDPI, Basel, Switzerland. This article is an open access article distributed under the terms and conditions of the Creative Commons Attribution (CC BY) license (http://creativecommons.org/licenses/by/4.0/). 